\title{
Um diálogo entre cinema, arte e ciência: pistas para uma crítica aos paradigmas da ciência moderna
}

\section{Isadora Ebersol}

Doutoranda; Universidade Federal de Pelotas; Pelotas, RS, Brasil isadora.ebersol@gmail.com

\section{Ana Paula Penkala}

Doutora; Universidade Federal de Pelotas; Pelotas, RS, Brasil penkala@gmail.com

\section{Resumo}

Neste trabalho buscamos fazer uma reflexão crítica sobre os processos de produção de conhecimento e sobre o estatuto epistemológico da ciência moderna e do fazer científico tomando a perspectiva de Vilém Flusser como ponto de partida. Questionamos seus regimes de verdade a partir do paralelo entre a crença na imagem cinematográfica e nas imagens técnicas e a crença na aparente objetividade do conhecimento científico. Encontramos pistas para uma crítica aos paradigmas da ciência moderna em abordagens que privilegiem outras formas de racionalidades e de relações com o mundo. A criação artística e poética se torna um desses caminhos através da racionalidade estético-expressiva, como proposta por Santos (2002), como também na hipótese das Ficções filosóficas, proposta epistemológica de Flusser de uma forma de conhecimento que dissolva as barreiras entre arte e ciência. Esses caminhos podem nos dar a chance de estabelecer uma dimensão estética para a ciência que supere seu aparente desencantamento e insuficiência para resolver os problemas do mundo. A partir da observação de filmes denominados como falsos documentários, refletimos sobre o poder que a ficção tem de enxergar a realidade que ultrapassa a verdade e no poder do pensamento que supere e modifique os limites da verdade de seu próprio tempo, atuando ele próprio como questionamento crítico das ordens de pensamento em voga.

\section{Palavras-chave}

Arte. Ciência. Falso Documentário. Ficções filosóficas. Vilém Flusser. 


\section{Introdução}

SONÊTO À CIÊNCIA

Ciência! Do velho tempo és filha predileta! Tudo alteras, com o olhar que tudo inquire e invade! Por que rasgas assim o coração do poeta, abutre, que asas tens de triste realidade?

Poderia ele amar-te, achar sabedoria em ti, se ousas cortar seu voo errante e ao léu quando tenta extrair os tesouros do céu, mesmo que a asa se eleve indômita e bravia? Edgar Allan Poe, À Ciência ${ }^{1}$

Tem sido possível perceber que as fronteiras entre o ficcional e o não-ficcional vêm se confundindo a tal ponto que abalam a aparente tranquilidade que o conceito moderno de verdade evoca. É nas fronteiras borradas entre a ficção e a não-ficção que residem alguns dos problemas atuais que enfrentamos no contexto midiático e informacional com a crescente disseminação de notícias falsas potencializada, dentre os muitos aspectos, pelos mecanismos de tratamento e manipulação digital das imagens, pela rapidez dos processos comunicacionais e pelas mídias digitais. Aliado a esses fatores, um complexo contexto geopolítico, econômico e cultural potencializa e viabiliza a descrença na ciência moderna como instância capaz de fornecer informações seguras e resolver os problemas do mundo. Embora atual, a relação entre os conceitos de fiç̧ão, imagens e verdade é um tema antigo que atravessa a filosofia desde Platão e percorre diversos momentos da história do pensamento (SELIGMANN-SILVA, 2016), tendo a própria noção de verdade se modificado nesse percurso. Acredita-se no que é dito, mas principalmente acredita-se no que é mostrado: o rastro da imagem fotográfica carrega o fantasma do real, fantasma que ainda hoje não conseguimos dissipar, especialmente em sua aderência às imagens em movimento. A ficção tem uma lógica de linguagem, assim como a verdade. São inúmeras as apropriações que as imagens em movimento fazem dessa linguagem, de modo a viabilizar ainda mais a aderência do real ao discurso visual. A partir dos filmes documentários é possível inventariar uma série de procedimentos e estratégias de linguagem que proporcionam essa relação que, no entanto, é feita de convenções. O que separa a "verdade" de um documentário "sério" da "verdade" de um falso documentário, portanto? Nosso

\footnotetext{
1 Publicado em: POE, Edgar Allan. Ficção completa: poesia \& ensaios. 1. ed. Rio de Janeiro: Companhia Aguilar, 1965. p. 925
} 
conhecimento prévio sobre seu estatuto, nossa aquiescência com seu discurso, nossa crença no conteúdo ou nosso costume com a linguagem?

Vilém Flusser, filósofo tcheco naturalizado brasileiro, já antecipava, em fins da década de 1980, muitas das questões que hoje vivenciamos envolvendo a relação humano/máquina e a produção de imagens no mundo contemporâneo. As imagens técnicas, como Flusser (2002) definiu as imagens produzidas através de aparelhos - como é o caso da imagem fotográfica e posteriormente da cinematográfica, televisiva e digital que a sucederam - inauguraram não só uma nova etapa da evolução técnica no modo de se produzir imagens, como um novo paradigma. Flusser estaria inserido no grupo de pensadores críticos que veriam na fotografia um marco a partir do qual um novo gesto, o de fotografar, sintetizaria uma ruptura não apenas técnica como também epistemológica associada a mudanças complexas na sociedade moderna e na relação entre técnica e produção de conhecimento. Para ele, abandonamos, com a fotografia e as imagens produzidas por aparelhos, a linearidade do pensamento histórico, causal, para entrarmos, então, no terreno do eterno retorno, da repetição, uma estrutura pós-histórica do nosso pensamento, conforme a define (FLUSSER, 2002). A ruptura paradigmática advinda da invenção da fotografia tem efeitos que ecoam na cultura ainda hoje e o aparelho fotográfico, para Flusser, seria apenas um precursor (e um modelo) de tantos outros aparelhos codificados que surgiriam depois e a partir dele. Analisar seu funcionamento nos permitiria compreender melhor o funcionamento de todos os aparelhos e, a partir deles, a relação contemporânea entre sociedade e imagens técnicas. Walter Benjamin, para quem a crítica à sociedade moderna é indissociável de uma teoria da técnica associada ao fazer artístico, também dedicou grande parte de sua teoria às imagens. Em seu texto clássico escrito em 1936 sobre a obra de arte na era da sua reprodutibilidade técnica, Benjamin (2014) fala sobre como a autenticidade da obra de arte se esvanece quando de sua reprodução técnica. Sobre essa que é uma das questões mais discutidas no campo da comunicação ainda hoje, Seligmann-Silva (2013) ressalta como o impulso de abandonarmos a busca por um original "puro e autêntico" abala as relações de reprodução e representação. No regime de verdade em que estamos inseridos, no entanto, confundimos as imagens técnicas com janelas objetivas para o mundo, das quais temos dificuldade em desconfiar:

Aparentemente, pois, imagem e mundo se encontram no mesmo nível do real: são unidos por cadeia ininterrupta de causa e efeito, de maneira que a imagem parece não ser símbolo e não precisar de deciframento. Quem vê 
imagem técnica parece ver seu significado, embora indiretamente. (FLUSSER, 2002, p. 14).

Em Filosofia da caixa preta: ensaios para uma futura filosofia da fotografia Flusser (2002) define "caixas pretas" como aparelhos produzidos através do conhecimento técnico e científico. Do funcionamento interno desses aparelhos pouco conhecemos, no entanto confiamos naquilo que ele produz tanto quanto confiamos no conhecimento científico do qual ele deriva. Flusser (2002, p. 15) ainda nos diz que "toda crítica da imagem técnica deve visar o branqueamento dessa caixa. Dada a dificuldade de tal tarefa, somos por enquanto analfabetos em relação às imagens técnicas. Não sabemos como decifrá-las [...]”. No ensejo dessa linha do pensamento de Flusser sobre as caixas pretas, buscamos, primeiramente, fazer uma reflexão crítica sobre os processos de produção de conhecimento e sobre o estatuto epistemológico da ciência moderna e do fazer científico. Para isso, questionamos seus regimes de verdade a partir do paralelo entre a crença na imagem cinematográfica e nas imagens técnicas e a crença na (aparente) objetividade do conhecimento científico. Dos seus processos, talvez pouco conheçamos, para além dos seus efeitos no mundo moderno e no nosso próprio funcionamento dentro desse mundo. Vivemos conforme seus paradigmas, confundimos conhecimento científico com conhecimento objetivo do mundo e caminho universal para a verdade, tal como fazemos com as imagens técnicas. Em um movimento aparentemente contrário, o que percebemos hoje é a crescente descrença e deslegitimação do conhecimento científico e até mesmo um pensamento anticientífico mais estrutural que opera no seio da sociedade. Tais movimentos são resultado, talvez, de insuficiência da própria ciência em estabelecer-se como um novo lócus do pensamento que viria com a pretensão iluminista de substituir o pensamento religioso, místico e mitológico que ocupava o lugar de explicar vida; bem como de sua dificuldade e até recusa em se aproximar da concretude da experiência vivida pelos sujeitos.

Seguimos um caminho que pretende demonstrar, a partir de Bruno Latour (1994), que, embora inseridos em um projeto moderno de "purificação" dos processos de produção de conhecimento que se esforça por manter a separação entre sujeito/objeto e natureza/cultura e a pureza de seus termos, esse mesmo projeto existe paralelo e simultaneamente a um outro movimento em que conhecimentos estão entrelaçados, são híbridos de natureza e cultura. Com Boaventura de Sousa Santos (2002) analisamos, em um primeiro momento, a confiança cega nos paradigmas da ciência moderna; para então 
aprofundarmos no que seria por ele chamado de período de transição paradigmática, que se apresenta visivelmente como crise, emergida de um desequilíbrio entre as promessas não cumpridas da modernidade e as cumpridas em excesso, como seria o caso da ciência. E então encontramos pistas para uma crítica aos paradigmas da ciência moderna em abordagens que privilegiem outras formas de racionalidades e de relações com o mundo que foram negligenciadas pela modernidade, como a racionalidade estético-expressiva, conforme apontado por Santos. Esse novo paradigma emerge junto a um conhecimento emancipatório que, ao se aproximar da criação artística e literária, estabelece uma dimensão estética para a ciência a fim de que supere seu aparente desencanto.

Uma dessas pistas, partindo de Flusser, aponta na direção das chamadas ficções filosóficas, o que pode ser compreendido como um projeto mais amplo do autor em torno de uma teoria do conhecimento que problematiza as cisões sujeito/objeto, ciência/arte, de forma a superar a crise da ciência moderna e torná-la mais consciente dos problemas epistemológicos que enfrenta. Reconhece que a objetividade e pureza almejadas por ela são ilusões forjadas no interior das suas próprias estruturas que, dialogando em eco consigo mesmas, deixam de dialogar com a experiência humana em sua concretude. 0 que sobra é vazio, é réplica sem destinatário, reprodução sem original:

Seu conhecimento extra-ético, extra-político, extra-estético é, na realidade, conhecimento des-estetizado, des-politizado, anestético, conhecimento truncado e, portanto, sem sentido, falso. Leva a abstrações de mais em mais isentas, não de valores, mas de sentido. (FLUSSER, 1998, p. 173).

Um paralelo pode ser visto nas observações de Bill Nichols, que nos sugere a prática documental como não isenta, enquanto dispositivo ou tecnicamente:

Esses filmes representam de forma tangível aspectos de um mundo que já ocupamos e compartilhamos. Tornam visível e audível, de maneira distinta, a matéria de que é feita a realidade social, de acordo com a seleção e a organização realizadas pelo cineasta. Esses filmes também transmitem verdades, se assim quisermos. (NICHOLS, 2005, p. 26-7, grifo nosso).

A hipótese epistemológica de Flusser, por ele mesmo considerada prematuramente otimista - ainda que possível - de dissolução das barreiras entre arte, ciência, ficção, imaginação, na direção de uma ciência aberta ao "momento estético" (FLUSSER, 1998, p. 
174) tem sido conhecida como epistemologia fabulatória ${ }^{2}$ a partir de um movimento um tanto quanto recente de "renovado interesse pela imaginação" (FELINTO, 2014, p. 6). Sobre ela, pesquisadores e teóricos têm se debruçado na medida em que passa a apontar cada vez mais em direções possíveis para resolver os problemas contemporâneos.

Por fim, nos perguntarmos se e como o potencial da ficção poderia ser utilizado para questionar a própria ciência e a aparente pureza e objetividade dos seus processos. Para isso, observamos brevemente alguns filmes que se utilizam de uma estrutura narrativa, estética e discursiva documental, evocando a crença através dos códigos de um discurso calcado na veracidade do que é dito e mostrado, para então questionarem, jogando a partir do seu interior e de suas regras, o próprio estatuto de verdade da imagem cinematográfica na sociedade. Questionando a própria performance com a qual a linguagem conta para produzir seus efeitos de realidade, criam ruído nos regimes de verdade aos quais as imagens técnicas se encontram vinculadas. Centramo-nos, nesta observação, em Verdades e Mentiras (1973), de Orson Welles; Opération Lune (2002) dirigido por William Karel; Isto é Spinal Tap (1984), de Rob Reiner.

\section{Sempre confie nos aviões: da confiança cega na ciência moderna à transição paradigmática}

Em Jamais fomos modernos, Bruno Latour (1994) defende que os conhecimentos estão em redes que se caracterizam por sua heterogeneidade. Para o autor, somos híbridos (de natureza e cultura) instalados precariamente no interior de instituições científicas. No entanto, e paradoxalmente, com o dever de mantermos nossa ciência pura, duplamente pura: pura de contato com a sociedade e pura de contato entre si. E por quê? Segundo Latour, porque somos modernos. Porque a modernidade exige que nossos tecidos não sejam mais inteiriços. Decidimos, pois, que a única forma de progresso seria garantida pela separação entre humanos e não-humanos, a clássica dicotomia ainda hoje tão referenciada entre sujeito/objeto, enfim, pela cisão entre mundo natural, portanto imutável e dado a ser descoberto, e o mundo social, construído, inventado e impuro. Sua tese, no entanto, é de que jamais fomos modernos, que nunca deixamos por completo a velha matriz antropológica dos

\footnotetext{
2 Sobre a epistemologia fabulatória flusseriana ver Zona cinzenta: imaginação e epistemologia fabulatória em Vilém Flusser (FELINTO, 2014), Ficções Filosóficas: a epistemologia subterrânea de Flusser (RIBEIRO; SANTOS, 2015) e ainda Ficção como fruto da falta de fundamento: a fenomenologia especulativa de Vilém Flusser (OLIVEIRA, 2018).
} 
povos considerados "pré-modernos", este tecido onde o conhecimento está interligado entre natureza e sociedade. Se essa cisão, que caracteriza a modernidade a partir dos ideais iluministas, nunca ocorreu de fato, então não seríamos modernos, nunca teríamos cumprido por completo as promessas da modernidade.

Logo, o que estaria em jogo, então, não seria a crise da modernidade e sim as ficções sobre as quais se fundam sua própria existência e as dicotomias e fragmentações do conhecimento que ela engendra em suas estruturas, necessárias ao seu discurso purificador, mas irrealizáveis na prática. Latour demonstra que o próprio movimento de "purificação" da ciência moderna necessita, para existir, ou seja, como parte constituinte dele mesmo, de um movimento contrário de "tradução" em que o corolário é a proliferação dos "híbridos" de natureza e cultura - conhecimentos em que ciência, política, técnica, ficção, arte, economia e sociedade se misturam no interior e como parte mesmo dos processos de construção da modernidade. Se estas duas práticas opostas, mas constituintes do discurso da modernidade, forem consideradas separadamente, então seremos realmente modernos e estaremos aderindo ao projeto da purificação ainda que ele só exista em paralelo com a proliferação destes que ele chama de "híbridos". Se, por outro lado, nos voltarmos para a interdependência e simultaneidade desses dois processos dentro do projeto da modernidade, então deixaremos de ser modernos, ao menos pela sua definição clássica, “[...] pois tomamos consciência, retrospectivamente, de que os dois conjuntos de práticas estiveram operando desde sempre no período histórico que se encerra [...]" e, então “[...] as relações tormentosas que estabelecemos com as outras naturezas-culturas seriam transformadas." (LATOUR 1994, p. 16). Assim como na célebre cidade de Macondo de Gabriel Garcia Marquez ${ }^{3}$, comunidade que cresce com quase nenhum contato com o mundo exterior, o moderno acha-se uniforme, imaculado, purificado e almeja um crescimento ascendente para o progresso. Assim como Macondo, novamente: uma cidade fictícia que vincula, no entanto, duas ordens de realidade: a ficção, não menos real que os fatos, e estes, não menos criados que a ficção.

Ao observar o cotidiano, teremos inúmeros exemplos do quanto confiamos na ciência a ponto de lhe confiarmos a nossa própria vida. Gostaríamos aqui de estabelecer uma comparação - que pode muito bem ser considerada um tanto quanto fabulatória e especulativa - sobre voar de avião e a nossa crença na ciência. Não podemos negar que o

3 MARQUEZ, Gabriel Garcia. Cem anos de solidão. 34aㅗ ed. Rio de Janeiro: Record, 1989. 
medo de andar de avião existe e até mesmo, para algumas pessoas, as impede de voar. Mas para uma boa parte que utiliza esse meio de transporte é necessário que o medo ceda seu lugar, no que for possível, à confiança nos mecanismos do próprio avião. As estatísticas, os relatórios técnicos e as empresas de aviação também ocupam um lugar privilegiado em demonstrar a segurança desse tipo de transporte. Por essa razão, milhares por dia entram em aviões que chegam a alcançar cerca de dez quilômetros de altitude. Não havendo crença no discurso técnico-científico, muitos nunca chegariam a cogitar entrar em uma máquina dessas. A ciência, inegavelmente, tem fundamental papel na segurança desses transportes, não é o objetivo aqui deslegitimar sua qualificação. No entanto, ao fim e ao cabo, o que muitas vezes nos separa da queda é o piloto, ou seja, o caráter humano. Suas decisões, sua experiência, sua comunicação, seu planejamento e imaginações futuras, suas relações interpessoais, seu estado psicológico, sua atenção, sua visão e a sua capacidade única, não totalmente previsível, de resolução dos problemas, todas articuladas no inefável instante do voar. Nossa ausência de medo, portanto, diz menos sobre nossa coragem do que sobre a crença no paradigma científico moderno. A ciência moderna convenceu-nos da sua infalibilidade, eficácia e eficiência, e o lugar central da matemática no conhecimento sobre as coisas fez com que "[...] conhecer signifique quantificar" (SANTOS, 2002, p. 63), o que pode explicar nossa crença na aparente objetividade das estatísticas, bem como nos aviões, cujos mecanismos que os sustentam, na verdade, bem pouco nos preocupam no cotidiano.

Segundo Santos (2002, p. 51) "no início do século XIX a ciência moderna já tinha se convertido em uma instância moral suprema, para além do bem e do mal", uma nova religião em cima da qual depositar-se-iam as crenças que antes recaíam sobre as explicações divinas. Uma instância capaz de resolver os problemas que só poderiam ser “[...] convenientemente resolvidos se fossem convertidos em problemas científicos ou técnicos" (SANTOS, 2002), operando no que o autor chama de "gestão científica da sociedade". Segundo Thomas Kuhn em $A$ estrutura das revoluções científicas (2013), as comunidades científicas no seu estado normal (ou seja, em momentos em que não operam revoluções científicas), são um instrumento eficiente em resolver problemas da vida moderna. É por esse motivo que nossa confiança em aviões não é de modo algum infundada. A ciência moderna foi eficaz em resolver alguns problemas, no entanto foi igualmente efetiva em criar outros inexistentes ou insignificantes até então, guardando perdas e ganhos resultantes do progresso científico e tecnológico moderno. 
Para Santos, no entanto, estamos atravessando um período de transição paradigmática que se apresenta visivelmente como crise, possivelmente um período que antecede uma revolução científica no entendimento proposto por Kuhn (2013). Santos considera que a modernidade cumpriu, até mesmo em excesso, algumas de suas promessas, enquanto deixou de cumprir outras. A ciência estaria nas promessas cumpridas em excesso. Este desequilíbrio seria uma das possíveis causas da crise do paradigma moderno. Os pilares sobre os quais para Santos estaria apoiada a modernidade - pilares da emancipação e da regulação - estariam desequilibrados com a "[...] absorção do pilar da emancipação pelo da regulação [...]" (SANTOS, 2002, p. 55) e a colonização dos diferentes tipos de racionalidades pela racionalidade cognitivo-instrumental da ciência, em síntese. Com a "ciência em excesso", todas as formas de conhecimento que fugirem aos seus princípios epistemológicos são negadas pelo paradigma dominante. Para Santos, o paradigma emergente desta crise residirá nas representações que a modernidade deixou em aberto, dentre elas a racionalidade estético-expressiva, e na procura de um desequilíbrio dinâmico que penda para a emancipação, ou seja, um conhecimento emancipatório o qual ele vai chamar de "conhecimento prudente para uma vida decente" (SANTOS, p. 107).

Este conhecimento emancipatório tenta fugir da racionalidade científica moderna de conquista do caos pela ordem; racionalidade que simplifica a realidade, visando prever comportamentos e reduzir complexidades, numerar para conhecer, descrever e ordenar, isolar objetos e sujeitos, desconfiar da experiência imediata, analisar em partes separadas e sintetizar o resultado em leis que possam ser generalizadas e universalizadas. Segundo Santos (2002, p, 79), é preciso “[...] que se aceite um certo nível de caos decorrente da negligência relativa do conhecimento-regulação [...]" para que o conhecimento-emancipação possa emergir.

Considerando que a ciência moderna não é a única explicação possível da realidade (SANTOS, 2002), há que privilegiar outras formas de conhecimento e de relações com o mundo. Pra Santos, o conhecimento emancipatório não descobre: cria. Nesse sentido, a proximidade com a criação literária e artística fica mais evidente e a ciência ganha uma dimensão estética. Assim como a ciência cria realidades através das quais pode existir e explicar o mundo, a poesia, as artes e a imaginação criam e reinventam realidades que são formas também válidas de elaborar e se relacionar com o mundo. Para o poeta Manoel de Barros em entrevista para o filme Janela da Alma (JARDIM; CARVALHO, 2001), "a imaginação é que transvê, que transfigura o mundo, que faz outro mundo, pro poeta e pro 
artista de um modo geral." Às vezes, tanto para o artista, quanto para o cientista, é preciso imaginar para descobrir a realidade que ultrapassa a verdade e que reside na ficção.

Ao contrário do que podemos supor, imaginação e rigor não ocupam lados opostos quando na criação de conhecimento por meios diversos daqueles que a ciência moderna considera como tradicionalmente rigorosos. Flusser (1998, p. 29), ao dizer que "o mundo da 'realidade' não passa de uma criação imperfeitamente rigorosa" convida o leitor do ensaio Mito do Cubo 4 a transpor a "realidade" e transformar-se em sal de cozinha, para então estabelecer o que chama de caricatura da nossa existência humana e dos nossos mitos cristãos e ocidentais a partir de uma série de proposições feitas ao leitor-sal-de-cozinha. Reconhece que, para tal empreendimento, nossa imaginação deve estar orientada pelo rigor do intelecto, pois "imaginação rigorosa é a mola mestra da atividade criadora" (FLUSSER, 1998, p. 29). Nesse sentido, segundo o autor, o mundo criado pela imaginação é passível de ainda mais rigor e alcança tanta ou mais consistência que o mundo pouco ou imperfeitamente rigoroso da "realidade". Sem pretender adentrar o vasto campo de estudos da imaginação, o que nos interessa é observar que o que está posto neste e em outros ensaios de Flusser, e talvez o tema que circunscreve boa parte de sua obra, consiste em uma profunda crítica à aparente objetividade do conhecimento científico e um questionamento acerca de sua própria ficcionalidade. Tal rigor imaginativo proposto por Flusser é necessário para que, ao empreendermos uma crítica aos paradigmas da ciência moderna e ao propormos um conhecimento científico que articule arte, imaginação, criação e ficção, não sejamos impelidos na direção de um pensamento anticientífico perigoso para o funcionamento da sociedade. Não se trata de apoiar a relativização do conhecimento a ponto de um "vale tudo" epistemológico. Se trata, antes, de considerar a ciência como objeto histórico e a crítica aos seus paradigmas como processo necessário e desejável na construção do rigor científico. Em outras palavras, a autoconsciência dos problemas filosóficos e epistemológicos é necessária à prática científica, conforme adverte Flusser (2011, p. 157), "[...] sob pena de continuarmos esbarrando, futilmente, contra a barreira da objetividade." Nossa posição contemporânea nos faz, ainda nas palavras de Flusser, ignorantes e ingênuos em meio à crise da ciência moderna; no entanto, é justamente por nos encontrarmos sob o dorso fraturado do tempo, exatamente no ponto de fratura que

\footnotetext{
4 Publicado originalmente no jornal O estado de S. Paulo em 1964 e posteriormente republicado em 1998 pela Editora Universidade de São Paulo, em uma coletânea de trinta e cinco ensaios de caráter fábulatório ou especulatório que receberam o título de Ficções Filosóficas.
} 
caracteriza nossa situação contemporânea, para citar Agamben (2009), que "podemos olhar o mundo que nos cerca como se ninguém jamais o tivesse olhado. Somos todos pioneiros." (FLUSSER, 2011, p. 157)

A alegoria de nossa confiança cega nos aviões, que representa a crença cega na ciência, sintoma moderno do qual dificilmente conseguiremos fugir, nos faz lembrar de outro trecho de Janela da Alma, no qual o escritor José Saramago se pergunta sobre como seria se estivéssemos todos cegos. A resposta a sua indagação ele mesmo dá alguns momentos depois: "Mas nós estamos realmente todos cegos. Cegos da razão, cegos da sensibilidade, cegos, enfim... de tudo aquilo que faz de nós não um ser razoavelmente funcional, no sentido da relação humana, mas ao contrário, em um ser agressivo, um ser egoísta, um ser violento...”. Para Santos (2002, p. 114), “a ciência moderna é uma forma de saber que se afirma desencantada e desapaixonada" na fria tarefa de distanciamento para que se evite romper o dualismo sujeito/objeto. Estaríamos, então, todos cegos de ciência?

Em $O$ ensaio sobre a cegueira, Saramago reflete:

Por que foi que cegámos, Não sei, talvez um dia se chegue a conhecer a razão, Queres que te diga o que penso, Diz, Penso que não cegámos, penso que estamos cegos, Cegos que vêem, Cegos que, vendo, não vêem. (SARAMAGO, 1995, p. 310);

\section{3 É tudo mentira: a ciência, a ficção e os regimes de verdade}

Foucault começa As palavras e as coisas (1999) expondo a impossibilidade do nosso pensamento ao citar Jorge Luis Borges e a sua classificação dos animais5. Segundo Foucault, os códigos de uma cultura fixam certas ordens empíricas de pensamento que só existem através de uma linguagem. Funcionam assim como funcionam as classificações: estabelecendo similitudes e encontrando diferenças. Foucault investiga sobre as ordens específicas em que se constituem os saberes, a partir de quais condições formam-se as racionalidades que hoje operam na ordem do conhecimento a qual conhecemos e da qual partilhamos. Investiga quais as condições de emergência e de possibilidade dos

\footnotetext{
5 "os animais se dividem em: a) pertencentes ao imperador, b) embalsamados, c) domesticados, d) leitões, e) sereias, f) fabulosos, g) cães em liberdade, h) incluídos na presente classificação, i) que se agitam como loucos, j) inumeráveis, k) desenhados com um pincel muito fino de pêlo de camelo, l) et cetera, m) que acabam de quebrar a bilha, n) que de longe parecem moscas'. No deslumbramento dessa taxinomia, o que de súbito atingimos, o que, graças ao apólogo, nos é indicado como o encanto exótico de um outro pensamento, é o limite do nosso: a impossibilidade patente de pensar isso." (FOUCAULT, 1999, p. IX)
} 
conhecimentos, a partir de quais rupturas e descontinuidades a ordem de conhecimento em que vivemos pôde surgir e de que forma poderá se desarticular até mudar ou desaparecer. Busca dar atenção para as rupturas epistemológicas ao longo da história do pensamento, não para achar uma causa primeira, mas antes para entender como as coisas começaram a ser pensadas da forma como se pensa hoje, como os objetos, as práticas e os saberes foram se constituindo no terreno do pensamento. Nesse movimento, Foucault investiga a partir de quais conhecimentos ou condições do pensamento os saberes das ciências humanas foram possíveis. Coloca, então, a problemática do humano, do sujeito, ou do seu surgimento enquanto objeto do pensamento: segundo ele, assim como surgiu, irá possivelmente perder importância e desvanecer. Com isso, coloca o sujeito como uma invenção recente fruto de mudanças nas disposições do saber.

A ciência é uma formação discursiva que cria regimes de verdade, talvez por isso a classificação dos animais no texto de Borges evidencie os limites e as impossibilidades do nosso próprio pensamento: está fora de uma ordem de pensamento da qual fazemos parte. É importante, no entanto, pensar nas condições históricas de possibilidade desses "regimes de verdade" que fazem com que possam surgir assim como possam desaparecer. Cada época traz consigo os limites daquilo que pode ser dito, de que forma pode ser dito, quem tem o poder de dizê-lo e qual o seu estatuto de verdade. Ou seja: a verdade é histórica. É a partir daí que surge a potência do pensamento que supere e modifique os limites da verdade de seu próprio tempo, atuando como questionamento e reflexão sobre as ordens de pensamento em voga. E se utilizássemos o lugar ficção para a desnaturalização dessas certezas que nos parecem tão assentadas? Mesmo quando se apresenta como verdade, a potencialidade da ficção reside em colocar um ruído no discurso considerado verdadeiro.

No ensaio Criação científica e artística6 ${ }^{6}$ Flusser (1998, p. 175) sugere que “[...] informação nova é criada por introdução de ruídos em informações redundantes" ao abrirse o velho para aquilo que ainda não foi articulado. Nesse sentido, toda a criação científica é, para Flusser, obra de arte e toda a criação artística é articulação de conhecimento, na medida em que ambos, cientista e artista, se abrem tanto para vivências como para conhecimentos novos. Essa ligação subterrânea que sempre uniu ciência e arte deve ser trazida para a consciência "[...] se quisermos ter vivências e conhecimentos plenamente humanos, isto é: políticos, intersubjetivos" (FLUSSER, 1998, p. 175). Ciência e arte, na

\footnotetext{
6 Conferência proferida na Maison de la Culture, Chalon s/Saône em 23 de março de 1982 e posteriormente publicada em Ficções Filosóficas (1998).
} 
concepção moderna dos termos, seriam horizontes abstratos no caminho do conhecimento concreto que, para Flusser, é o conhecimento intersubjetivo. 0 caráter humano que a ciência moderna procurou isolar e afastar na sua pretensão de um conhecimento transcendente e objetivo se encontra, dessa forma, inevitavelmente imbricado na produção de todo conhecimento. Os horizontes da ciência e da arte são como vias de acesso a essa concreticidade do conhecimento que se realiza politicamente, no sentido da política como o campo concreto de inter-relações humanas. O divórcio moderno entre ciência e arte resultaria na destruição do campo político, no sentido plenamente humano dessa relação. Ultrapassar essa cisão seria, então, uma forma não somente de libertar a ciência moderna de sua crise epistemológica como ultrapassar a crise da sociedade ao libertá-la do perigo da tecnocracia, conforme adverte Flusser. 0 que parece apontar para a solução dessa crise, em suas palavras é "síntese de ciência e arte sob o signo da política, e superação da técnica por ciência informada pela arte e arte informada pela ciência." (FLUSSER, 1998, p. 176). Não é difícil perceber o caráter de atualidade e urgência, mas também de complexidade e rigor que essa tarefa demanda.

Em Verdades e mentiras (F for Fake, 1973), Orson Welles, diretor do filme, se coloca frente à câmera como um mágico ou um charlatão enquanto fala diretamente ao espectador que toda a história é certamente um tipo de mentira. Welles utiliza da narrativa e da estrutura documental para criar um falso documentário sobre um famoso falsário de obras de arte conhecido por reproduzir perfeitamente obras de Matisse, dentre outros pintores. Duplamente falso: desde a temática da falsidade até a forma do falso documentário, arte, realidade, e ficção estão misturados na narrativa de Welles. 0 filme questiona a própria crença na imagem e no discurso cinematográfico, bem como a relação íntima entre criação artística e realidade e a tão discutida questão da autoria no campo da arte. 0 que é típico de Welles, no entanto, é sua crítica à busca inexorável da verdade como ideal do pensamento, na medida em que toda a história, como ele alerta, assim como todo o conhecimento, são uma espécie de ficção.

Welles tinha, em 1973, uma larga experiência em estressar o real e o ficcional de forma que produzissem sentidos que ele, posteriormente, tratava de observar, analisando a maneira com que esses conceitos estavam imbricados nos discursos midiáticos. Não é novidade para quem estuda comunicação sua polêmica encenação de Guerra dos Mundos, de H. G. Wells, em uma transmissão de rádio. Na época, 1938, dispunha de um texto de ficção, um canal de mídia, sua linguagem e um público que - ainda não inserido no universo 
das imagens como aquele que, na década de 70, já havia crescido diante da TV e estava conhecendo a tecnologia videográfica cada vez mais profundamente - não possuía certas "proteções" contra as estratégias ali postas por Welles. Essas "proteções" seriam o conhecimento prévio de um jogo narrativo e o domínio da linguagem, ainda que iniciante. Embora avisasse, em vários momentos, que se tratava de uma encenação, a própria estrutura da narrativa se confundia com a de uma transmissão real de um acontecimento “ao vivo". A "verdade”, portanto, estava colada, indissociável, ao “conteúdo” ficcional. Só aqueles que dominavam o texto de Guerra dos Mundos ou conheciam as intenções de Welles poderiam separar a linguagem da verdade do conteúdo fictício sem ter acesso aos apostos (ou seja, elementos em espaço off da estrutura da narrativa) que avisavam ser uma radionovela. Os falsos documentários, portanto, são construídos dessa mesma maneira, ao considerarem o que é próprio da linguagem documental. "A tradição do documentário está profundamente enraizada na capacidade de ele nos transmitir uma impressão de autenticidade." (NICHOLS, 2005, p. 20) Ela depende de garantias circunstanciais de veracidade e conta com uma noção prévia de sua linguagem. 0 conhecimento que o espectador carrega implicitamente sobre a gênese da imagem está diretamente relacionado com sua crença no "real" que a imagem fotográfica (parada ou em movimento) mostra, como sugere Jacques Aumont (2006).

A exemplo de Welles, Opération Lune é um falso documentário de 2002 dirigido por William Karel sobre a operação Apolo 11 da National Aeronautics and Space Administration (NASA), responsável pela visita humana à lua em 1969. Traz entrevistas com políticos dos Estados Unidos, com o astronauta Edwin Aldrin e com o cientista espacial e diretor técnico da NASA na época, Farouk El-Baz, dentre outros envolvidos com a missão. Conta também com depoimentos de Christiane Kubrick, viúva do cineasta Stanley Kubrick, a fim de construir a tese de que Richard Nixon, presidente estadudinense na época, contratara Kubrick para gravar artificialmente as imagens da primeira pessoa a pisar na lua. 0 filme, que mantém uma relação de proximidade narrativa com a famosa teoria conspiratória de que a ida à lua teria sido uma farsa, não questiona precisamente este fato, mas sim a produção de material imagético sobre o evento por parte do governo dos EUA. Segundo a teoria exposta nos moldes narrativos de um documentário expositivo - entrevistas, imagens de arquivo e voz over - as imagens que comprovariam a operação teriam sido perdidas, o

\footnotetext{
7 Originalmente exibido no canal de televisão franco-alemão Arte em 2002.
} 
que faria com que o governo tivesse de produzir ficcionalmente as provas de sua missão, a fim de que a crença na imagem divulgada garantisse a crença no próprio feito. Novamente, o que comumente chamamos forma e o que chamamos conteúdo se misturam: através do documentário falso ele questiona a possibilidade de falsificação de imagens que mudem o curso da história. Se cairmos no truque e acreditarmos na sua veracidade, o filme já tem sua tese comprovada. Aos depoimentos que evocam o caráter de oficialidade, como os de políticos, técnicos e cientistas, somam-se depoimentos de personagens fictícios. 0 espectador que, nesse ponto, já confia no dispositivo documental produzido pelo filme, não questiona a veracidade de entrevistas como as do produtor da Paramount, Jack Torrance e do astronauta David Bowman, para citar alguns, nem a relação de seus nomes com personagens conhecidos de filmes do Kubrick ${ }^{8}$. Esse detalhe reafirma a ideia de que o conhecimento prévio ou contextual do espectador é esperado ou, pelo contrário, indesejável para que a aparência de verdade do falso documentário produza seus efeitos.

Entrevistas de pessoas públicas e políticos são apresentadas em edições de poucos segundos, amarradas pela voz over que alinha toda a narrativa, construindo sua própria verdade. É somente nos créditos finais que Opération Lune releva seus personagens fictícios, erros de gravação e entrevistas oficiais sem edição, desbancando o caráter documental construído até então. Com isso, questiona não só a possibilidade de manipulação de imagens que carregam efeitos de verdade a fim de criar qualquer discurso que se pretenda defender, como discute a relação complexa entre produção de imagens, conhecimento técnico e científico, política e ideologia ao expor um fato histórico onde estes pilares estiveram intimamente ligados, como o caso da corrida armamentista na Guerra Fria. É importante notar, também, o quanto o filme parece ser ao mesmo tempo um grande deboche sobre as teorias conspiratórias e um sinal de alerta do quão fácil é deixar-se enganar por elas, uma espécie de aviso de incêndio dos problemas contemporâneos.

Em 1984 o diretor Rob Reiner lança Isto é Spinal Tap (This is Spinal Tap), documentário "musical" que acompanhava a carreira da banda de metal-glam-rock Spinal Tap. Hoje reconhecido como um dos mais importantes mockumentaries (documentários falsos, não raro com intuito jocoso), o filme de Reiner combinou a circunstância do estilo musical de nicho, do senso comum sobre astros do rock (seus exageros, por exemplo) e atores desconhecidos, somando-se a isso a oportunidade, à época não tão comum, de

\footnotetext{
8 Jack Torrance faz referência ao protagonista do filme O Iluminado (1980) e David Bowman é o nome do comandante da nave Discovery no filme 2001 uma Odisséia no Espaço (1968).
} 
acompanhar o dia-a-dia de um grupo musical em início de carreira. Se, por um lado, as performances dos atores eram engraçadas e esse detalhe se misturava aos mitos sobre esse tipo de músico; a linguagem documental estava intacta, com todos os seus elementos preservados. Presume-se, portanto, que Spinal Tap seja uma banda real e que o documentário, portanto, esteja centrado na "verdade", porque seu "conteúdo" é verdadeiro. 0 que é papel da linguagem documental e o que é papel dessa crença prévia e circunstancial com aquilo que as imagens mostram? Se a estrutura da narrativa é igual a do que poderíamos entender como "acesso ao real", e portanto é somente o "conteúdo" que nos possibilita questionar o que se veicula como "verdade", então qualquer coisa pode ser verdade - desde que os envolvidos na sua forja não deixem que se saiba dessas circunstâncias. Na ciência, temos diversos exemplos que fizeram e ainda fazem o caminho da banda Spinal Tap. ${ }^{9}$

O cinema encontrou um meio através dos falsos documentários de questionar seu estatuto de verdade a partir do seu próprio interior e jogando com suas próprias regras. A utilização do falso, da mentira e da ficção dentro de uma estrutura narrativa e visual como a do documentário que evoca a crença na veracidade do que é dito pode criar ruídos que questionem a aparente objetividade da imagem técnica frente a uma sociedade que a supervaloriza. Será que é possível, a exemplo dos falsos documentários, criar ruídos dentro da produção científica que utilizem o potencial da ficção para questionar a própria ciência, sua pureza, a aparente objetividade dos seus processos? Flusser conclui: "Tais respostas, e outras possíveis, são redutíveis a uma: liberdade é jogar contra o aparelho. E isto é possível" (FLUSSER, 2002, p. 75).

Sobre esse texto, de caráter exploratório, apenas podemos dizer: é tudo mentira! Mas dizemos a verdade. Assim como Orson Welles (1973) em Verdades e mentiras:

\footnotetext{
${ }^{9}$ A indústria alimentícia, principalmente a de carne e a de laticínios, empregam muito esforço e dinheiro na manipulação de realidades de forma a aumentar o consumo de seus produtos, não raro financiando "estudos" que confirmam seu discurso, como aponta o livro Uma verdade indigesta: como a indústria alimentícia manipula a ciência do que comemos (2019), de Marion Nestle. Já em abril de 2020 surgiram denúncias sobre a relação dos governos de Donald Trump, nos EUA, e Jair Bolsonaro, no Brasil, com as empresas que produzem os medicamentos com a substância cloroquina, fortemente contraindicada pelos cientistas e profissionais da saúde em vários países, porém indicada por esses governos, com o endosso de "artigos científicos", para tratamento de pessoas infectadas pelo Sars-Cov2. Sobre isso, ver: https://www.forbes.com/sites/lisettevoytko/2020/04/07/trump-has-small-distant-link-to-sanofi-french-drugmaker-ofhydroxychloroquine/\#58228e517260, https://www.metropoles.com/brasil/por-ordem-de-bolsonaro-exercito-ja-fez-maiscloroquina-do-que-em-10-anos e https://www.metropoles.com/brasil/politica-brasil/empresario-que-produz-acloroquina-e-militante-bolsonarista. Acesso em: 25 maio 2020. Tais relações entre ciência, política e economia reforçam a teoria de Latour (1994) de que o fato científico está imbricado em redes de interesses múltiplos que são ao mesmo tempo naturais, discursivas e sociais.
} 
Senhoras e senhores, para fins de introdução, este é um filme sobre trapaça, fraude, sobre mentiras. Contadas no mercado da arte e agora em um filme, quase todas as histórias são certamente um tipo de mentira. Mas não nesse filme. Isso é uma promessa. Durante a próxima hora, tudo que vocês irão ouvir de nós é realmente verdade e baseado em fatos sólidos.

\section{Considerações finais}

Assim como as ordens de realidade nas quais a imagem cinematográfica se encontra presa ao carregar o rastro do real advindo do estatuto da fotografia, o conhecimento científico se encontra ligado aos regimes de verdade do paradigma científico moderno, sua aparente objetividade, neutralidade e pureza, que não são mais suficientes para explicar o mundo e suas relações e, segundo os autores, talvez nunca tenham sido, de fato. Encontramos pistas para uma crítica aos paradigmas da ciência moderna em abordagens que privilegiem outras formas de racionalidades e de relações com o mundo. A criação artística e poética se torna um desses caminhos através da racionalidade estéticoexpressiva, como proposto por Santos. No mesmo sentido, as potencialidades contidas em epistemologias como as de Flusser, suas ficções filosóficas, muito ainda têm a contribuir com a ciência e com os processos de produção de conhecimento. Esses caminhos podem nos dar a chance de estabelecer uma dimensão estética para a ciência que supere seu aparente desencantamento e insuficiência para resolver os problemas do mundo. Onde encontrar esse caminho, quais os cuidados e quais as vigilâncias epistemológicas precisamos ter ao trilhá-lo? Dada a complexidade do problema e o recorte do trabalho, limitamo-nos a delinear apenas alguns desses aspectos, enquanto diversos outros restam em aberto.

Reconhecemos o poder que a ficção e a criação artística e poética têm de enxergar a realidade que ultrapassa a verdade e, a exemplo dos falsos documentários, do pensamento que supere e modifique os limites da verdade de seu próprio tempo, atuando ele próprio como questionamento crítico das ordens de pensamento em voga. No entanto, devemos ter cuidado ao trilhar esse caminho para não contribuirmos ainda mais com a deslegitimação do pensamento científico, sob o risco de vermos novamente o mundo ser fundamentado a partir de teorias e explicações conspiratórias e obscurantistas, de onde, a duras penas, a ciência moderna nos tirou. Ao criticar a ciência moderna, devemos ter claro, também, que não podemos jogar fora todos os seus paradigmas e julgar inúteis todos os seus processos, 
no entanto, temos a possibilidade de jogar dentro de suas próprias regras, a fim de problematizar o estatuto epistemológico do fazer científico.

\section{Referências}

AGAMBEN, Giorgio. 0 que é o contemporâneo? E outros ensaios. Chapecó: Argos, 2009.

AUMONT, Jacques. A imagem. 11 Ed., Campinas: Papirus, 2006.

BENJAMIN, Walter. A obra de arte na época de sua reprodutibilidade técnica. 2. Reimp. Porto Alegre: Zouk, 2014.

FELINTO, Erick. Zona Cinzenta: Imaginação e Epistemologia Fabulatória em Vilém Flusser. In: 23o Encontro Anual da Associação Nacional dos Programas de Pós-Graduação em Comunicação - COMPÓS. Anais [...]. Belém: Universidade Federal do Pará, 2014. Disponível em: http://compos.org.br/encontro2014/anais/. Acesso em: 22 maio 2020.

FLUSSER, Vilém. Filosofia da caixa preta: Ensaios para uma futura filosofia da fotografia. Rio de Janeiro: Relume Dumará, 2002.

FLUSSER, Vilém. Ficções filosóficas. São Paulo: Universidade de São Paulo, 1998.

FLUSSER, Vilém. Natural:mente: vários acessos ao significado de natureza. 1. Ed. São Paulo: Annablume, 2011.

FOUCAULT, Michel. As palavras e as coisas: uma arqueologia das ciências humanas. 8. Ed. São Paulo: Martins Fontes, 1999.

ISTO É SPINAL TAP. Direção: Rob Reiner. Roteiro: Christopher Guest, Michael McKean, Harry Shearer, Rob Reiner. EUA, 1984. (82 min). son., color. This is Spinal Tap.

JANELA da alma. Direção: João Jardim e Walter Carvalho. Roteiro: Walter Carvalho e João Jardim. Brasil, 2001. (73 min.), son., p\&b e color.

KUHN, Thomas S. A estrutura das revoluções científicas. 12. Ed. São Paulo: Perspectiva, 2013.

LATOUR, Bruno. Jamais fomos modernos: ensaio de antropologia simétrica. 1 a Ed. Rio de Janeiro: Editora 34, 1994.

NICHOLS, Bill. Introdução ao documentário. Campinas: Papirus, 2005.

OPÉRATION lune. Direção: William Karel. França, 2002. (52 min.), son., color.

POE, Edgar Allan. À ciência. In: POE, Edgar Allan. Ficção completa: poesia \& ensaios. 1. Ed. Rio de Janeiro: Companhia Aguilar, 1965. 
SANTOS, Boaventura de Sousa. Para um novo senso comum: a ciência, o direito e a política na transição paradigmática. Vol. 1 - A crítica da razão indolente: contra o desperdício da experiência. 4. Ed. São Paulo: Cortez, 2002.

SARAMAGO, José. Ensaio sobre a cegueira. 1. Ed. São Paulo: Companhia das Letras, 1995.

SELIGMANN-SILVA, Márcio. A teoria da fotografia em Walter Benjamin na era da síntese técnica de imagens. Cadernos Walter Benjamin, Fortaleza, v. 17, p. 12-36, jul-dez, 2016.

SELIGMANN-SILVA, Márcio. Ficção e imagem, verdade e história: sobre a poética dos rastros. Dimensões, Vitória, v. 30, p. 17-51, 2013.

VERDADES e mentiras. Direção: Orson Welles, Gary Graver, Oja Kodar, François Reichenbach. Roteiro: Orson Welles. França-Irã-Alemanha, 1973. (89 min.) son., color. F for Fake.

\title{
A dialogue between cinema, art, and science: clues to a critique of the paradigms of modern science
}

\begin{abstract}
In this work we make a critical reflection on the processes of knowledge production and the epistemological status of modern science and scientific practice, taking Vilém Flusser's perspective as a starting point. We question their regimes of truth based on the parallel between belief in cinematographic image and technical images and belief in the apparent objectivity of scientific knowledge. We found clues for a critique of the paradigms of modern science in approaches that favor other forms of rationality and relations with the world. Artistic and poetic creation becomes one of these paths through aestheticexpressive rationality, as proposed by Santos (2002), as well as in the hypothesis of Philosophical Fictions, Flusser's epistemological proposal of knowledge that dissolves the barriers between art and science. These paths can give us the chance to establish an aesthetic dimension for science that overcomes its apparent disenchantment and insufficiency to solve the world's problems. From the observation of films called false documentaries (mockumentaries), we reflect on the power that fiction has to see the reality that surpasses the truth and on the power of thought that surpasses and modifies the limits of the truth of its own time, acting itself as critical questioning of thought orders in vogue.
\end{abstract}




\section{Keywords}

Art. Science. False Documentary (mockumentaries).

Philosophical fictions. Vilém Flusser.

Recebido em 29/05/2020

Aceito em 24/08/2020 